\title{
Axillary arteriovenous fistula for the palliation of complex cyanotic congenital heart disease: Is it an effective tool?
}

\author{
Luis G. Quiñonez, MD, ${ }^{a}$ Morgan L. Brown, MD, ${ }^{\mathrm{b}}$ Joseph A. Dearani, MD, ${ }^{\mathrm{b}}$ Harold M. Burkhart, MD, ${ }^{\mathrm{b}}$ and \\ Francisco J. Puga, MD
}

\begin{abstract}
Objective: Patients with complex cyanotic congenital heart disease and a bidirectional cavopulmonary connection who are not candidates for or had failed Fontan operation may experience progressive cyanosis. An axillary arteriovenous anastomosis may be constructed to augment pulmonary blood flow. This report reviews our results with this approach in this complex group of patients.
\end{abstract}

\begin{abstract}
Methods: The records of patients with previous cavopulmonary connections who underwent a surgical anastomosis between the axillary artery and the vein for palliation of severe progressive cyanosis were reviewed.

Results: Eleven patients were identified. The median age at the time of the axillary arteriovenous anastomosis was 19.2 years (7.97-41.75 years). Seven patients were not candidates for the Fontan operation, and 4 patients had failed Fontan surgery. Three of the anastomoses were constructed with a side-to-side technique, and 8 anastomoses were constructed with a short interposition graft. Median fistula size was $5 \mathrm{~mm}(3-6 \mathrm{~mm})$. There was no operative mortality and 1 late death. Median survival was 2.85 years $(0.01-7.22$ years). All fistulae were patent at follow-up. Median preoperative arterial oxygen saturation was $84 \%(80 \%-86 \%)$ and $82 \%(76 \%-88 \%)$ at follow-up $(P=.38)$. Median preoperative hemoglobin was $18.5 \mathrm{~g} / \mathrm{dL}(11.7-22.6 \mathrm{~g} / \mathrm{dL})$ and $19.2 \mathrm{~g} / \mathrm{dL}$ $(14.6-22.6 \mathrm{~g} / \mathrm{dL})$ at follow-up $(P=.97)$. Median preoperative systemic ventricular ejection fraction was $51 \%$ $(27 \%-60 \%)$ and $46.5 \%(28 \%-60 \%)$ at follow-up $(P=1)$. Significant functional improvement was seen in only 1 patient.
\end{abstract}

Conclusions: In patients with complex cyanotic congenital heart disease who are not candidates for or had failed Fontan operation, palliation with an axillary arteriovenous fistula did not improve cyanosis or polycythemia. Functional outcome and ventricular ejection fraction did not improve or deteriorate. (J Thorac Cardiovasc Surg 2011;141:188-92)

The Fontan procedure provides good long-term palliation for patients with a single ventricle and complex cyanotic congenital heart disease. ${ }^{1,2}$ However, Fontan palliation may not be achievable in all patients. Some patients who have undergone previous cavopulmonary connections may not be candidates for Fontan completion. There are also those who may have had a failed Fontan surgery. The superior cavopulmonary connection, with or without additional sources of pulmonary blood flow, may provide adequate palliation. ${ }^{3}$ However, increasing cyanosis resulting from inadequate pulmonary arterial blood flow or development of pulmonary arteriovenous fistulae may cause further deterioration of their clinical condition. ${ }^{4}$ Construction of an axillary arteriovenous (AAV) anastomosis has been used in an effort to improve and stabilize their clinical condition. ${ }^{5-8}$

From the University of Alberta Stollery Children's Hospital, ${ }^{\text {a }}$ Edmonton, Alberta, Canada; and Mayo Clinic Foundation, ${ }^{\mathrm{b}}$ Rochester, Minn.

Disclosures: Authors have nothing to disclose with regard to commercial support.

Received for publication Aug 9, 2009; revisions received Nov 11, 2009; accepted for publication Dec 3, 2009; available ahead of print July 9, 2010.

Address for reprints: Luis G. Quiñonez, MD, University of Alberta Hospital, 8440 112th Street, Edmonton, Alberta, Canada T6G 2B7 (E-mail: quinonez.luis@ gmail.com).

$0022-5223 / \$ 36.00$

Copyright (C) 2011 by The American Association for Thoracic Surgery doi:10.1016/j.jtcvs.2009.12.059
We reviewed our experience with surgically created AAV fistulae in patients with patent superior cavopulmonary connections who were found not to be candidates for completion of the Fontan procedure or patients who had failed Fontan operation.

\section{MATERIALS AND METHODS Patients}

We identified 11 patients with complex cyanotic congenital heart disease with superior cavopulmonary connections ( 5 classic and 6 bidirectional) and subsequent creation of an AAV fistula. Their medical records were reviewed retrospectively. Institutional review board approval was obtained for this study.

All patients had an AAV fistulae constructed between 2000 and 2007 at the Mayo Clinic, Rochester. All patients were cyanotic and polycythemic with related complications. Symptoms included fatigue or weakness $(\mathrm{n}=7)$, headaches $(\mathrm{n}=3)$, and strokes or transient ischemic attacks $(n=5)$. Only 1 patient was using home oxygen. Four patients had known pulmonary arteriovenous malformations diagnosed by catheterization $(\mathrm{n}=3)$ and echocardiography $(\mathrm{n}=1)$.

Seven patients were not candidates for Fontan palliation. The reasons for not proceeding with the Fontan pathway were multiple and complex and involved significant clinical judgment. The principal reasons are given. One patient had severe bilateral pulmonary artery hypoplasia, and 1 patient had discontinuous central pulmonary arteries. One patient had pulmonary hypertension with an ejection fraction (EF) of $52 \%$, and he refused heart-lung transplantation. Three patients had an EF of less than $50 \%$ and were thought to have an overall high risk for the Fontan. One patient 


\author{
Abbreviations and Acronyms \\ $\mathrm{AAV}=$ axillary arteriovenous \\ $\mathrm{EF}=$ ejection fraction \\ $\mathrm{Hb}=$ hemoglobin \\ PTFE $=$ polytetrafluoroethylene \\ $\mathrm{SaO}_{2}=$ arterial oxygen saturation
}

had an EF of $27 \%$ and was triaged to heart transplantation. The other 2 patients had an EF of $40 \%$ to $45 \%$.

Four patients had undergone Fontan surgery. One patient still had her Fontan circuit. This patient could not tolerate catheter device closure of her fenestration. Two patients had their Fontan conduits taken down acutely because of early postoperative hemodynamic deterioration and renal failure. A final patient had the Fontan circuit taken down 9 years later because of thrombus in the conduit and in an effort to relieve protein-losing enteropathy. All other measures had failed, including Fontan revision (performed elsewhere) and fenestration. This patient also had problems with gastrointestinal bleeding, making anticoagulation difficult.

\section{Operation}

All operations were performed under general anesthetic via an infraclavicular approach. The pectoralis major muscle was split along its fibers, and the axillary artery and vein were isolated and controlled after systemic heparinization. Care was taken to avoid injury to the brachial plexus. With the exception of 1 patient, the ipsilateral side to the superior cavopulmonary connection was chosen to maximize arterial flow through the connection. The contralateral side was chosen in 1 patient because of an ipsilateral subclavian vein obstruction. Imaging of the axillary artery and vein was obtained by 1 or more methods, usually visualized at the time of echocardiography or angiography. If there is any doubt about the patency of these vessels, we consider a vascular ultrasound or venography.

Three AAV fistulae were performed using a direct side-to-side anastomosis, and $8 \mathrm{AAV}$ fistulae were performed with a polytetrafluoroethylene (PTFE) graft, per the surgeons' preference. The PTFE graft was kept as short as possible to minimize resistance and avoid distortion of the artery and vein $(<10 \mathrm{~mm})$. The median fistula size was $5 \mathrm{~mm}$ (range, $3-6 \mathrm{~mm}$ ). A 3-mm side-to-side fistula was used in an 8-year-old patient, and a $3.5-\mathrm{mm}$ graft was used in a 12.8-year-old patient. The rest of the fistulae were 5 to $6 \mathrm{~mm}$, and the patients' ages ranged from 13.8 to 41.8 years. Six fistulae were constructed on the left side. No patient had bilateral vena cavae. The factors taken into consideration to determine the size of the fistula were the patient's size, the size of the axillary artery and vein, and the potential risk of excessive volume loading the single functional ventricle. The axillary vein distal to the fistula was not ligated.

\section{Statistical Analysis}

Median values for arterial oxygen saturation $\left(\mathrm{SaO}_{2}\right)$, hemoglobin $(\mathrm{Hb})$, and systemic ventricular EF were compared using the rank sum method.

\section{RESULTS}

The median age at the time of AAV fistula construction was 19.2 years (range, $7.97-41.75$ years) (Table 1). There were 5 female patients. All had complex cyanotic congenital heart disease. The median time interval from the cavopulmonary connection to AAV fistula was 13.5 years (range, 0.11-41.32 years). Patients had a median of 4 operations (range, 2-7) before AAV fistula creation.
There were no operative deaths. None of the patients required admission to the intensive care unit. There were no early complications. Ten patients were followed after hospital dismissal. The median follow-up period was 2.85 years (range, 0.01-7.22 years). There was 1 late death from cardiac and renal failure 6.33 years after the AAV fistula. This patient had pulmonary hypertension and refused heart-lung transplantation. He had a bidirectional cavopulmonary connection. One patient was lost to follow-up because he returned to his home country.

Follow-up levels of $\mathrm{SaO}_{2}$ and $\mathrm{Hb}$ were available in 8 patients. The median preoperative $\mathrm{SaO}_{2}$ was $84 \%$ and was not significantly different than the dismissal or the followup $\mathrm{SaO}_{2}$ at $83 \%$ and $82 \%$, respectively $(P=.41$ and $P=.38$ ) (Figure 1). The median preoperative $\mathrm{Hb}$ level of $18.5 \mathrm{~g} / \mathrm{dL}$ was also not significantly different compared with the follow-up $\mathrm{Hb}$ level of $19.2 \mathrm{~g} / \mathrm{dL}(P=.97)$ (Figure 2).

The median ventricular EF, measured by echocardiography, in 7 patients with available data did not significantly change in the follow-up period $(51 \%-46.5 \%, P=1)$ (Figure 3). When grouped into New York Heart Association classes I/II and III/IV, 1 patient improved, 1 patient deteriorated, and the remaining patients were unchanged. Two patients were assessed for transplantation because of poor ventricular function and significant symptoms. One refused heart-lung transplantation and represents our single death in the series. The other patient is alive and remains in stable condition.

Four patients had further interventions during the followup period. One patient had an additional central shunt to his left pulmonary artery. Two patients had balloon dilation of the right subclavian vein. In 1 of these patients, the fistula was on the left side, opposite the side of the cavopulmonary connection. Another patient had a balloon dilation and stenting of the proximal right pulmonary artery. None of the patients have had heart or heart-lung transplantation.

In 8 patients with available follow-up, the AAV fistulae were demonstrated to be open by catheterization $(n=2)$, echocardiography $(\mathrm{n}=2)$, or physical examination $(n=4)$. Two patients had ipsilateral arm swelling. In 1 of these patients, this was associated with venous thrombosis. Another patient had ipsilateral arm numbness. One patient had mild facial swelling and headaches. There were no other complications attributed to the fistula.

\section{DISCUSSION}

Our findings did not demonstrate a clinically or statistically significant improvement in symptoms, $\mathrm{SaO}_{2}$, or $\mathrm{Hb}$ levels after the creation of an AVV fistula in patients with complex cyanotic congenital heart disease and cavopulmonary connections. The AAV fistulae were constructed in an effort to palliate and improve symptoms, cyanosis, and polycythemia. These findings are not consistent with the 
TABLE 1. Patient demographics and diagnoses

\begin{tabular}{lcl}
\hline Patient & Age $(\mathbf{y})$ & \multicolumn{1}{c}{ Diagnosis } \\
\hline 1 & 8.0 & $\begin{array}{c}\text { Dextrocardia, situs inversus, } \\
\text { unbalanced AVSD, PA } \\
\text { DILV, PA, DORV }\end{array}$ \\
2 & 12.8 & DILV, L-TGA, VSD \\
3 & 13.8 & PA-IVS, TA \\
4 & 16.7 & PA-IVS \\
5 & 17.4 & PA-IVS \\
6 & 19.2 & TA \\
7 & 20.3 & Heterotaxy, single ventricle \\
8 & 22.6 & Heterotaxy, DORV, discontinuous \\
9 & 36.8 & pulmonary arteries \\
& & Criss-cross heart, D-TGA, AVSD \\
10 & 38.8 & Univentricular heart, nonconfluent \\
11 & 41.8 & pulmonary arteries \\
\hline
\end{tabular}

$L V$, Left ventricle; $R V$, right ventricle; $D I$, double inlet; $D O$, double outlet; $P A$, pulmonary atresia; $I V S$, intact ventricular septum; $D-T G A$, dextro-transposition of the great arteries; $T A$, tricuspid atresia; $A V S D$, atrioventricular septal defect; $V S D$, ventricular septal defect.

conclusions of other published series. ${ }^{5-8}$ Nevertheless, we did not observe significant clinical deterioration in this group of patients. We do not know how the construction of an AAV fistula may alter the modified natural history of this difficult and complex group of patients.

In 1972, Glenn and Fenn ${ }^{5}$ reported supplementing pulmonary blood flow with an AAV fistula in patients with previous classic cavopulmonary artery shunt. The Birmingham Children's Hospital group concluded that a brachial artery to basilic vein fistula provides the same benefits of supplementing pulmonary blood flow with fewer complications. ${ }^{6}$ Kopf et al, ${ }^{7}$ from Yale University, observed improvements in oxygen saturations after AAV fistula creation. Most recently, Magee et al, ${ }^{8}$ from Toronto Sick Children's Hospital, reported the benefits in oxygen saturation and $\mathrm{Hb}$ levels after an AVV fistula in a group of patients.

Technical factors may account for the lack of significant improvement in our cohort. In our patients, the relative size of the AVV fistula may have been inadequate to augment pulmonary blood flow. The median fistula size in our patients was $5 \mathrm{~mm}(3-6 \mathrm{~mm})$, with a median patient age of 19.2 years. The Toronto group describes a 6- to 7 -mm AVV fistula in an overall younger group of patients with a median age of 12.5 years. ${ }^{8}$ In 8 of our patients the fistula was created with a PTFE graft, which may have added resistance to flow. In the Toronto series, the fistulae were made with a side-to-side anastomosis. ${ }^{8}$ Our recent and preferred technique is to use an PTFE graft between the artery and the vein because it gives a more precise and consistent fistula size compared with a side-to-side anastomosis. We are reticent to use a large shunt because of the potential of excessive volume loading of a single ventricle.

We did not ligate the distal axillary vein, as described by the Toronto group. This may have decreased the amount of effective blood flow through the cavopulmonary connection. Ligation of the axillary vein distal to the fistula may be done to prevent arm swelling. We have not found this to be a significant problem, because only 2 of our patients had arm swelling. Ligation of the vein may cause problems by further increasing venous pressures in the head and neck causing facial swelling and headaches. Ligation of the vein may also lead to the development of large superficial venous collaterals to drain the arm, obviating the potential benefits of ligation. We believe that the potential problems with ligation of the distal axillary vein outweigh the theoretic benefits.

Effective palliation for patients with single ventricles can be achieved with cavopulmonary connections, with or without additional sources of pulmonary blood flow. ${ }^{3}$ This approach may be chosen when a patient is not a candidate for Fontan palliation or has failed the Fontan. Comparable survival outcomes have been published when comparing this approach with the Fontan. ${ }^{9}$ However, progressive cyanosis can be a problem with the presence of a cavopulmonary connection. The causes of failure are the development of decompressing systemic venous collaterals, the development of pulmonary arteriovenous fistulae, or increased pulmonary vascular resistance from the development of systemic-topulmonary collaterals. ${ }^{4}$ Our older patients may have had many of these problems, which may partially explain the lack of observed benefit in our series.

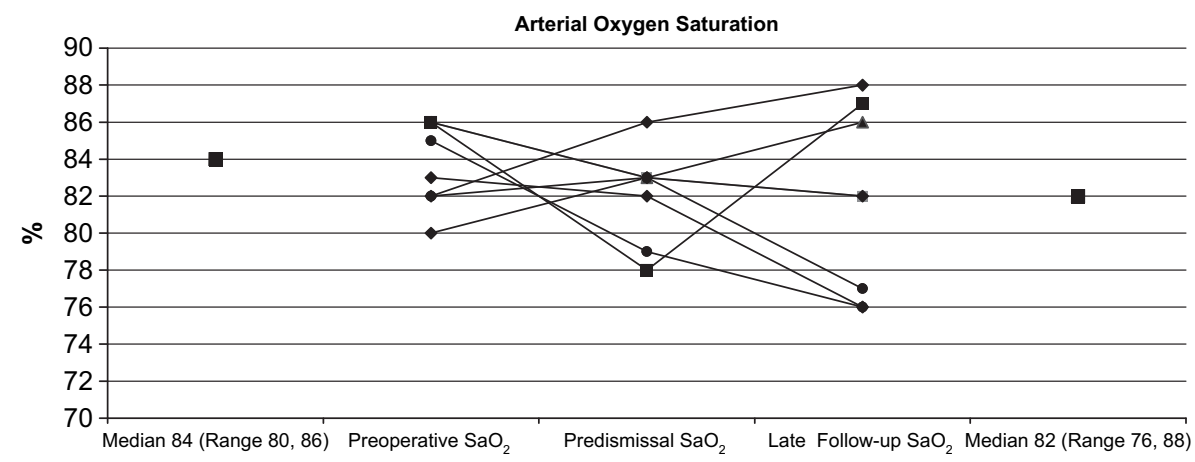

FIGURE 1. $\mathrm{SaO}_{2}$ levels before and after axillar arteriovenous fistula in 8 patients. Some values overlap between patients. $\mathrm{SaO}_{2}$, Arterial oxygen saturation. 


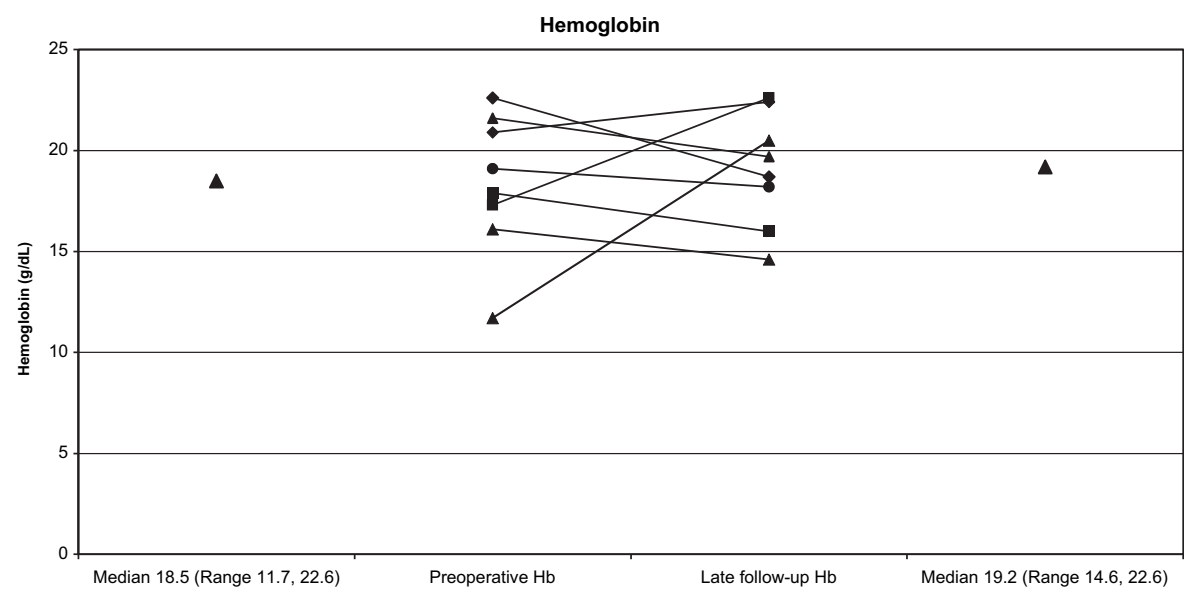

FIGURE 2. Hb level before and after AAV fistula in 8 patients. $H b$, Hemoglobin.

There are potential advantages of an AAV fistula to augment pulmonary blood flow through a cavopulmonary connection. We found that the fistula can be made with ease and without hospital morbidity or mortality. The extrathoracic approach obviates the need for repeat sternotomy in this difficult patient population. The AAV fistula may provide hepatic factor to the lung vasculature, thereby decreasing the quantity and development of pulmonary arteriovenous fistulae. ${ }^{10}$ This could be a mechanism for the improvement seen by other investigators. We do not have the imaging data to confirm this finding. However, when we analyzed the 4 patients with pulmonary arteriovenous malformations, we did not see an improvement in their $\mathrm{SaO}_{2}$. The AAV fistula may also increase the size of the pulmonary arteries by adding pulsatility, thereby improving pulmonary blood flow. ${ }^{11}$

There are potential disadvantages to the AAV fistula. There is the risk of volume loading the single ventricle with the additional blood flow. ${ }^{12} \mathrm{We}$ did not observe deterioration in ventricular function with the additional blood flow from the fistula. Another problem may be dilation of the caval vein and superior vena cava syndrome. ${ }^{12}$ Only 1 of our patients had mild facial swelling and headaches. Finally, arm swelling was seen in only 2 patients in our series.
The single death in our series was in a patient with compromised ventricular EF and significant functional impairment. He refused heart-lung transplantation but lived more than 6 years. There was reasonable continued survival in our cohort. Our longest survivor has lived more than 7 years after his fistula. We do not know whether the creation of an AAV fistula alters the natural history of these complex patients, in relation to survival or future need for heart or heart-lung transplantation. There is no available comparison group because any patient who is symptomatic and significantly cyanotic with no other correctible cause would receive a fistula at the Mayo Clinic.

Four patients had additional interventions after their AAV fistula surgery. All of these interventions sought to enhance flow through the cavopulmonary connection or provide additional blood flow through the pulmonary arteries. It is important to continue to look for causes of desaturation in these complex patients. The increased pressure in the superior vena cava after the creation of the AAV fistula may predispose to the development of decompressing systemic venous collaterals. Optimal and unobstructed systemic blood flow to the SVC should be maintained. The development of pulmonary artery stenoses should be corrected. In patients with a classic Glenn shunt, blood flow to the contralateral lung should be ensured.

Ventricular Ejection Fraction

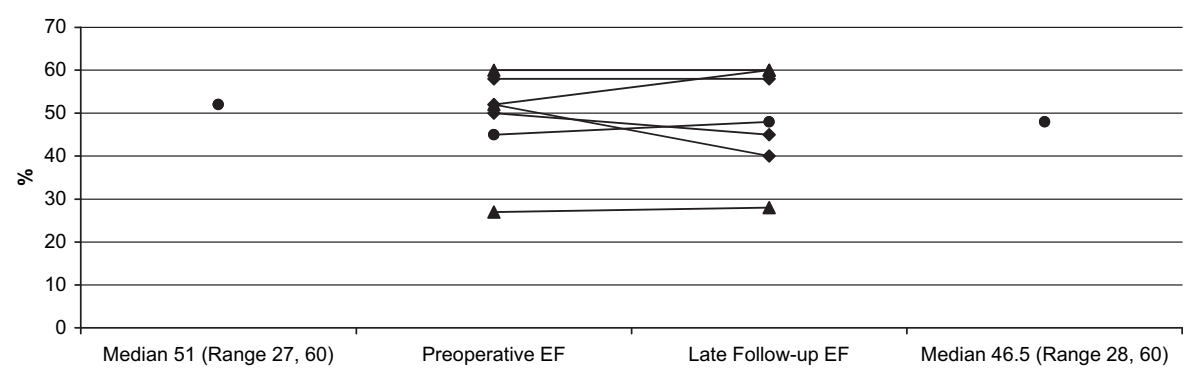

FIGURE 3. Ventricular EF before and after AAV fistula in 7 patients. $E F$, Ejection fraction. 


\section{Limitations}

Our study is a retrospective analysis of a small cohort of patients from a single institution. Because of the small numbers of patients, it is difficult to compare subgroups, such as patients with classic versus bidirectional cavopulmonary connections. The patients are heterogeneous and highly complex. There is no similar group of patients available for comparison.

\section{CONCLUSIONS}

In patients with complex cyanotic congenital heart disease who are not candidates for or have failed a Fontan operation, the construction of an AAV fistula may improve effective pulmonary blood flow but does not improve cyanosis or polycythemia. There was no deterioration in ventricular $\mathrm{EF}$ or functional outcome with a reasonable continued survival. The age of our patient cohort, the relative size of the AAV fistula, and the technique of surgery may explain our findings.

The patients for whom this operation is considered present infrequently. Furthermore, they have few, or no, options. Despite our findings, we continue to offer this form of palliation because we have found that these patients' conditions do not deteriorate with this operation. Each of these infrequent cases needs to be evaluated individually for any modification in our technical approach. Nevertheless, the use of the fistula may stabilize a deteriorating condition, even if improvement is not observed. There are no data to prove this contention, given the lack of a comparison group.

\section{References}

1. Driscoll DJ. Long-term results of the Fontan operation. Pediatr Cardiol. 2007;28: 438-42.

2. Bartz PJ, Driscoll DJ, Dearani JA, Puga FJ, Danielson GK, O'Leary PW, et al. Early and late results of the modified Fontan operation for heterotaxy syndrome 30 years of experience in 142 patients. $J$ Am Coll Cardiol. 2006;48:2301-5.

3. Calvaruso DF, Rubino A, Ocello S, Salviato N, Guardì D, Petruccelli DF, et al. Bidirectional Glenn and antegrade pulmonary blood flow: temporary or definitive palliation? Ann Thorac Surg. 2008;85:1389-95.

4. Freedom RM, Yoo S-J, Williams WG. Chapter 35: The cavopulomnary shunt. In: Freedom RM, Yoo S-J, Mikailian H, Williams WG, eds. The Natural and Modified History of Congenital Heart Disease. 1st ed. New York: Blackwell Publishing Inc/Futura Division; 2004:435-48.

5. Glenn WW, Fenn JE. Axillary arteriovenous fistula. A means of supplementing blood flow through a cava-pulmonary artery shunt. Circulation. 1972;46:1013-7.

6. Mitchell IM, Goh DW, Abrams LD. Creation of brachial artery-basilic vein fistula. A supplement to the cavopulmonary shunt. J Thorac Cardiovasc Surg. 1989;98:214-6.

7. Kopf GS, Laks H, Stansel HC, Hellenbrand WE, Kleinman CS, Talner NS. Thirty-year follow-up of superior vena cava-pulmonary artery (Glenn) shunts. J Thorac Cardiovasc Surg. 1990;100:662-70.

8. Magee A, Sim E, Benson LN, Williams WG, Trusler GA, Freedom RM. Augmentation of pulmonary blood flow with an axillary arteriovenous fistula after a cavopulmonary shunt. J Thorac Cardiovasc Surg. 1996;111:176-80.

9. Day RW, Etheridge SP, Veasy LG, Jenson CB, Hillman ND, Di Russo GB, et al. Single ventricle palliation: greater risk of complications with the Fontan procedure than with the bidirectional Glenn procedure alone. Int J Cardiol. 2006; 106:201-10.

10. McElhinney DB, Marshall AC, Lang P, Lock JE, Mayer JE Jr. Creation of a brachial arteriovenous fistula for treatment of pulmonary arteriovenous malformations after cavopulmonary anastomosis. Ann Thorac Surg. 2005;80:1604-9.

11. Miyaji K, Shimada M, Sekiguchi A, Ishizawa A, Isoda T. As originally published in 1996. Usefulness of pulsatile bidirectional cavopulmonary shunt in high-risk Fontan patients. Updated in 2002. Ann Thorac Surg. 2002;74:971-2.

12. Berdat PA, Belli E, Lacour-Gayet F, Planché C, Serraf A. Additional pulmonary blood flow has no adverse effect on outcome after bidirectional cavopulmonary anastomosis. Ann Thorac Surg. 2005;79:29-36. 